\title{
DESENVOLVIMENTO DE APLICATIVOS PARA BIBLIOTECAS A PARTIR DE ASPECTOS DA ARQUITETURA DA INFORMAÇÃO
}

\author{
Erik André de Nazaré Pires \\ Bibliotecário-Documentalista UFPA \\ erikpires@ufpa.br \\ Jorge Moisés Kroll do Prado \\ Doutorando em Ciência da Informação - UFSC \\ jorge.exlibris@gmail.com
}

Resumo

\begin{abstract}
O artigo discute como os aplicativos móveis podem ser utilizados em bibliotecas, visando uma aproximação maior com o interagente. A pesquisa tem no seu escopo, como abrangência geral: mostrar quais as observações necessárias para a elaboração de aplicativo para biblioteca; quanto aos segmentos específicos: evidenciar o contexto para a inserção de aplicativos em bibliotecas e explicar de que forma a arquitetura da informação é usada para aplicativos; quanto ao percurso metodológico e operacional: utilizar, no primeiro momento, a pesquisa bibliográfica, e, em seguida, valer-se de um caráter exploratório, em virtude da sua característica de potencial contribuição para a comunidade biblioteconômica. Além disso, suscita como inquietação: como as bibliotecas podem desenvolver aplicativos atrativos e eficientes para os interagentes? Por fim, este trabalho pretende proporcionar observações sobre o desenvolvimento de aplicativos para dispositivos móveis, os quais podem ser fatores que proporcionem funcionalidade e visibilidade para as bibliotecas.
\end{abstract}

Palavras-chave: Tecnologias da Informação e Comunicação. Aplicativos móveis. Bibliotecas. Dispositivos móveis.

\section{INTRODUÇÃO: SOCIEDADE CONECTADA}

Atualmente, vive-se na sociedade global, interconectada, na qual as relações, na maioria das vezes, são realizadas por meio da virtualidade. Essa conectividade, palavra que faz parte do vocabulário da maioria das pessoas, mesmo sabendo que a internet ainda não alcance grande parte da população mundial, é uma realidade permanente e constante.

Quando se fala em conexão virtual, pensa-se em comunicação de imediato, seja por meio de e-mails, web conferência, chats, blogs e as tão famosas e utilizadas redes sociais, pois são ferramentas que proporcionam um estreitamento nas relações tanto pessoais quanto profissionais. Diante desse contexto, percebe-se que muitas experiências se dão em uma realidade em que a globalização se torna presente na vida de grande parte da população, formando uma sociedade global ou sociedade em rede que, de acordo com Castells (2005, p. 20), é vista da seguinte maneira:

[...] em termos simples, é uma estrutura social baseada em redes operadas por tecnologias de comunicação e informação fundamentadas na microeletrônica e em redes digitais de computadores que geram, processam e distribuem informação a partir de conhecimento acumulado nos nós dessas redes.

Entrando no cenário das tecnologias que visam dinamizar as atividades das bibliotecas, tem-se o dispositivo móvel que é designado popularmente em inglês por handheld, sendo um computador de bolso habitualmente equipado com um pequeno ecrã (output) e um teclado em miniatura (input). Atualmente, essas tecnologias são uma realidade constante e consolidada e os bibliotecários, em suas atividades profissionais, podem fazer uso dessas ferramentas de forma proficiente (TERUEL, 2010). 
Os aplicativos móveis têm a característica de oferecer serviços e produtos que visam facilitar para o interagente o acesso à informação de que estão necessitando, atendendo, dessa forma, um dos principais objetivos de qualquer biblioteca: a disseminação da informação. Nesse sentindo, a biblioteca exerce o papel de atuação como instituição social que abrange um espaço para o desenvolvimento da comunidade na qual se insere, com forte participação na criação de conhecimento, ampliando seu papel para além de disseminar informações.

A facilidade no acesso à informação é outra vertente importante quando se trata de disseminação, pois antes de divulgar, é preciso que o registro (representação temática e descritiva da informação) seja feito de maneira correta e eficiente, ou seja, a recuperação da informação, que é o processo de pesquisa, localização e apresentação de documentos em um sistema de informação. A pesquisa é feita por meio da formulação de estratégias de busca para identificação e localização de documentos e/ou seus metadados (VIEIRA; PINHO 2015) e deve ser realizada de maneira que proporcione $\mathrm{o}$ atendimento informacional satisfatório dos interagentes.

$\mathrm{O}$ uso da informação alcançada por meio dos documentos obtidos proporciona a construção de um novo conhecimento, formando um ciclo ininterrupto de produção de conhecimento, como se pode verificar por meio do seguinte ciclo: construção, comunicação e uso. Lembrando que os dispositivos móveis participam de maneira significativa nesse âmbito, uma vez que essas tecnologias podem armazenar documentos que serão usados pelos interagentes, como por exemplo: e-readers.

A partir dessa concepção de interação e dinamismo no acesso informacional, os dispositivos móveis surgem também para auxiliar na construção do conhecimento. Para que isso possa ocorrer, uma das prerrogativas é o acesso a documentos com textos completos disponíveis nessas tecnologias para que o interagente possa acessar, codificar e decodificar o que está armazenado nesses documentos e assim, tenha a possibilidade de produzir novos conhecimentos.

A partir desse cenário interconectivo que o século XXI proporciona, o seguinte estudo tem o fito geral configurado da seguinte maneira: mostrar quais são as observações necessárias para a elaboração de aplicativos móveis para biblioteca; quanto aos segmentos específicos tem-se a seguinte configuração: evidenciar o contexto para inserção de aplicativos móveis em bibliotecas, explicar de que forma a arquitetura da informação é usada para aplicativos e expressar como o mercado e as opiniões têm um papel importante perante $o$ desenvolvimento de aplicativos.

A pesquisa científica tem o pressuposto de proporcionar ao pesquisador inquietações quanto ao transcurso de como será desenvolvida, e, nesse caso em específico, aborda-se como os aplicativos móveis podem potencializar e estreitar as relações com os interagentes, valendo-se de uma ferramenta que é utilizada em larga escala no mundo, nas mais diversas instituições e organizações. A partir desse contexto, chega-se à seguinte indagação: como as bibliotecas podem abranger aspectos no sentido de desenvolver aplicativos atrativos e eficientes para os interagentes?

Partindo desse questionamento, a pesquisa objetiva contribuir para o contexto biblioteconômico, no sentido de apresentar observações para se desenvolver aplicativos móveis. Consequentemente, as bibliotecas podem conquistar mais interagentes, no que diz respeito à utilização de serviços e produtos disponíveis nos aplicativos móveis.

Nos ditames do percurso metodológico e operacional, far-se-á, primeiramente, uma pesquisa bibliográfica que, segundo Lakatos e Marconi (2005, p. 183), "abrange a bibliografia já tornada pública em relação ao tema de estudo, desde publicações avulsas, boletins, jornais, revistas, livros, pesquisas, monografias, teses, material cartográfico etc.", sendo o primeiro passo para a construção da pesquisa científica. Quanto ao seu escopo, se caracteriza como um estudo de abordagem exploratória, pois possui em seu cerne "o objetivo de reunir dados, informações, padrões, ideias ou hipóteses sobre um problema ou questão de pesquisa com pouco ou nenhum estudo anterior" (BRAGA, 2007, p. 25), constituindo, dessa forma, uma pesquisa que visa contribuir de forma significativa para o contexto biblioteconômico.

\section{APLICATIVOS E BIBLIOTECAS: UM CONTEXTO}


As bibliotecas, instituições que ao longo da sua história tiveram como pressupostos a guarda da memória do que é registrado, principalmente no que tange aos livros, são de suma importância, por realizar a gestão informacional. Ressaltando que, atualmente, a gestão híbrida da informação (impresso e eletrônico) faz parte do contexto das bibliotecas.

$\mathrm{O}$ tradicionalismo pelo gerenciamento dos registros impressos sempre foi característica marcante das bibliotecas; entretanto, pode-se perceber que, ao longo da história, houve mudanças de suportes tradicionais como pergaminho, papiro e papel, mas a finalidade continua a mesma: preservação da memória coletiva, ou seja, as bibliotecas são instituições de grande valia para a humanidade.

Os séculos foram passando e as bibliotecas tiveram que acompanhar o ritmo de mudanças que transcorrem com a sociedade; consequentemente, os suportes informacionais foram avançando para o segmento tecnológico, surgindo os aplicativos móveis, que:

São um tipo de software concebido para desempenhar tarefas práticas ao usuário para que este possa concretizar determinados trabalhos. Esta característica distingue-o de outros tipos de programas, como os sistemas operativos (que são os que fazem funcionar o computador), as linguagens de programação (que permitem criar os programas informáticos em geral) e os utilitários (que realizam tarefas de manutenção ou de uso general) (NEIL, 2010, p. 35).

Hoje são tidos como tecnologias de fácil utilização e que simplificam o acesso para quem deseja obter informações sobre algum serviço ou produto. Servem para inúmeras atividades cotidianas, tais como fonte de pesquisa, informações sobre artista preferido, encontrar um lugar que se está procurando, possibilitar contato direto com pessoas ou com as lojas e serviços que mais se utiliza, resultando em infinitas possibilidades de uso (NEIL, 2010).

No que se refere ao Brasil, ainda se encontra com poucas experiências de utilização (BARROS, 2012). Diante dessa perspectiva, percebe-se que esse tipo de tecnologia não está sendo aplicado com afinco nas bibliotecas pelo fato delas não possuírem conhecimentos e habilidades para desenvolver aplicativos móveis ou até mesmo não ter disponível uma boa equipe de Tecnologia da Informação que venha dar suporte a este desenvolvimento. Como benchmarking, podemos destacar alguns exemplos nacionais (Quadro 1) e internacionais (Quadro 2) de aplicativos de bibliotecas.

Quadro 1 - Aplicativos nacionais e suas funcionalidades

\begin{tabular}{|c|l|}
\hline APLICATIVO/INSTITUIÇÃO & \multicolumn{1}{|c|}{ DESCRIÇÃO } \\
\hline Universidade de Caxias do Sul & $\begin{array}{l}\text { Deficativo da Universidade de Caxias do Sul (Biblioteca UCS) é } \\
\text { astante simples. É o primeiro aplicativo desenvolvido para biblioteca } \\
\text { universitária no Brasil. Oferece alguns recursos como renovação de } \\
\text { materiais, fotos e tutoriais em vídeo; também permite compartilhar } \\
\text { determinado conteúdo com opções de curtir e comentar. A última } \\
\text { atualização ocorreu em maio de 2012. O número aproximado de } \\
\text { instalações é de até mil. }\end{array}$ \\
\hline Universidade Estadual Paulista (UNESP) & $\begin{array}{l}\text { A UNESP apresenta dois aplicativos não oficiais que são iniciativas de } \\
\text { usuários, mas oferecem serviços básicos para biblioteca. O aplicativo da } \\
\text { Universidade Estadual Paulista é nomeado como Biblioteca Unesp; é } \\
\text { possível fazer renovação de materiais e foi desenvolvido de forma } \\
\text { independente, não sendo vinculado à instituição ou projetos. Foi } \\
\text { atualizado pela última vez em janeiro de 2014. Foram realizados, } \\
\text { aproximadamente, cinco mil downloads. Outro aplicativo é o UpBook } \\
\text { UNESP que também oferece o serviço de renovação de livros, além de } \\
\text { oferecer lembrete para o usuário do vencimento da devolução. É de } \\
\text { autoria independente e sua última atualização foi em abril de 2014, sendo } \\
\text { ońmero de instalações próximo dos quinhentos. }\end{array}$ \\
\hline
\end{tabular}




\begin{tabular}{|c|l|}
\hline $\begin{array}{c}\text { Pontifícia Universidade Católica do Rio Grande } \\
\text { do Sul (PUCRS) }\end{array}$ & $\begin{array}{l}\text { O aplicativo da PUCRS é voltado para toda a universidade, oferecendo } \\
\text { diversos recursos para os alunos, incluindo acesso aos serviços básicos da } \\
\text { biblioteca, como renovação e reserva. O aluno pode utilizar os serviços } \\
\text { do aplicativo como consulta de notas, que permite ver as notas de cada } \\
\text { matéria do período atual e anteriores; grade de horários, a qual fornece } \\
\text { detalhes do local e duração da aula; e verificação das mensalidades que } \\
\text { foram pagas e as que estão pendentes. A última atualização foi feita em } \\
\text { novembro de 2013, com número estimado próximo a cinquenta mil } \\
\text { instalações. }\end{array}$ \\
\hline \multirow{5}{*}{ Universidade Presbiteriana Mackenzie } & $\begin{array}{l}\text { A Mackenzié é uma das universidades com sistema Pergamum que utiliza } \\
\text { a versão mobile para oferecer acesso a serviços de sua biblioteca. A } \\
\text { diferença do aplicativo com relação aos demais é que não é necessário } \\
\text { fazer o download, somente acessar o link por meio do navegador do } \\
\text { elular. É possível renovar, consultar o acervo e verificar o que está } \\
\text { reservado. Também é possível alterar algumas configurações, como o } \\
\text { idioma: inglês, espanhol e português. }\end{array}$ \\
\hline Universidade Federal do Espírito Santo & $\begin{array}{l}\text { Oaplicativo também não é oficial da Universidade Federal do Espírito } \\
\text { Santo, mas permite buscas no catálogo, adição de obras como favoritas, } \\
\text { verificação do que está reservado e emprestado. A última atualização foi } \\
\text { eita em março de 2014, com número de mil instalações, } \\
\text { aproximadamente. }\end{array}$ \\
\hline
\end{tabular}

Fonte: Bastos (2014)

Estes aplicativos nacionais oferecem uma gama diversificada de serviços e produtos que vão desde o acesso ao catálogo, perpassando pela utilização de chat; o que demonstra que seu desenvolvimento pode ter praticidade e interatividade satisfatória para os interesses dos interagentes. $\mathrm{O}$ mesmo se assemelha ao contexto internacional.

Quadro 2 - Aplicativos internacionais e suas funcionalidades

\begin{tabular}{|c|l|}
\hline INSTITUIÇÃO & \multicolumn{1}{|c|}{ DESCRIÇÃO } \\
\hline Universidade de Salamanca & $\begin{array}{l}\text { A universidade de Salamanca, situada na cidade de Salamanca na Espanha, também } \\
\text { oferece um aplicativo, o Biblio USAL. É uma universidade tradicional e seu aplicativo } \\
\text { oferece serviços básicos, como: acesso ao catalogo online (OPAC), dados das bibliotecas } \\
\text { (horário de funcionamento, localização e acesso ao site), detalhes dos serviços prestados } \\
\text { por cada unidade (notícias, atividades realizadas por cada biblioteca etc). Em serviços } \\
\text { oferece ajuda para os usuários, opções de comutação, empréstimo domiciliar, serviço de } \\
\text { referência, cursos, entre outros recursos que podem ser importantes informar que a } \\
\text { instituição realiza. Sua última atualização ocorreu em fevereiro de 2013, e o número de } \\
\text { instalações feitas é de aproximadamente cinco mil. }\end{array}$ \\
\hline Bibliotecas de Barcelona & $\begin{array}{l}\text { O aplicativo das Bibliotecas de Barcelona, o BibliosBCN, mostra atividades realizadas } \\
\text { por várias bibliotecas na cidade. Apresenta agenda com todas as atividades do dia e } \\
\text { detalhes; faz busca das atividades que aconteceram em bibliotecas próximas da } \\
\text { localização do usuário. Possui calendário com as atividades agendadas do mês. Ainda } \\
\text { disponibiliza o mapa da cidade com todas as bibliotecas, oferecendo detalhes sobre as } \\
\text { atividades e a localização, telefone e e-mail da biblioteca onde ocorrerão os eventos. } \\
\text { Permite ao usuário adicionar suas preferências. É um aplicativo simples, mas que } \\
\text { consegue agregar serviços oferecidos por várias bibliotecas, possibilitando ao usuário } \\
\text { uma escolha, e também saber o que acontece nas bibliotecas de toda cidade. Com } \\
\text { instalações estimadas em dez mil, sua última atualização foi em dezembro de 2013. }\end{array}$ \\
\hline Universidade de Sheffield
\end{tabular}




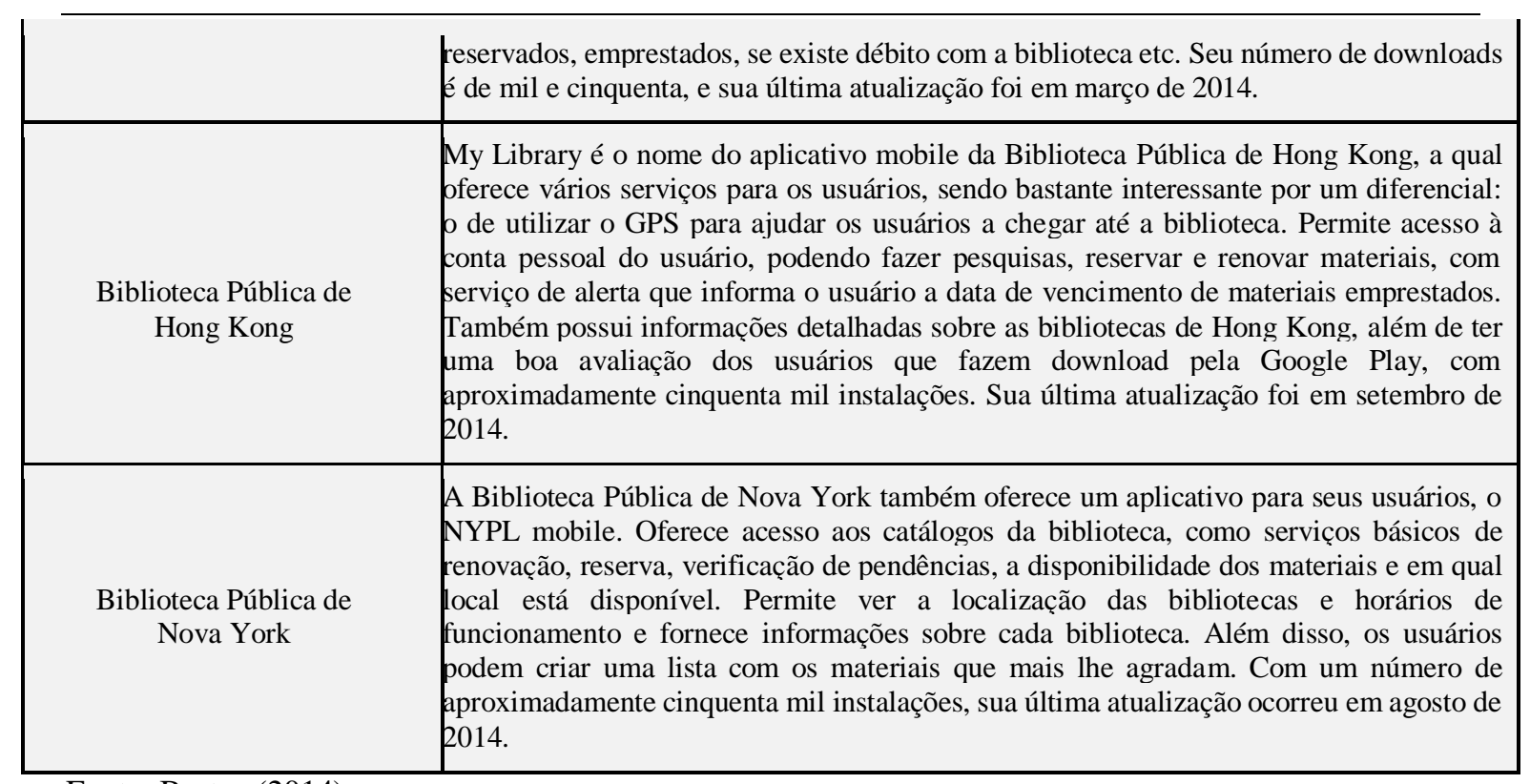

Fonte: Bastos (2014)

Todos os aplicativos apresentam acesso ao catálogo, o que evidencia a preocupação em disponibilizar ao interagente o acesso às informações que estão disponíveis nos catálogos das referidas instituições. Além desse serviço, também existem outras funcionalidades que se pode considerar como diferenciadas, como por exemplo, o GPS, evidenciando que o aplicativo mobile “ $[\ldots]$ pode ser considerado um recurso diferenciado, que não tem a intensão de substituir uma página na internet, nem ser tão completo quanto o próprio sistema da biblioteca" (BASTOS, 2014, p. 33); é uma ferramenta tecnológica de fácil utilização, em que as instituições elaboram um planejamento adequado para que o seu uso seja efetuado de forma consistente.

\section{ARQUITETURA DA INFORMAÇÃO DE APLICATIVOS}

A estrutura tecnológica em que a tipologia informacional ficará armazenada deve ser desenvolvida de maneira que a usabilidade seja favorável ao interagente. Os sistemas de recuperação da informação devem ser intuitivos e com layout agradável, pois proporcionarão conforto e praticidade para quem for utilizá-los para realizar pesquisa e, consequentemente, recuperar informação que atenda à necessidade informacional do indivíduo.

Atualmente, tem-se os preceitos da Arquitetura da Informação (AI) que, segundo Lima-Marques e Macedo (2006, p. 245), são "o escutar, o construir, o habitar e o pensar a informação como atividade de fundamento e de ligação hermenêutica de espaços, desenhados ontologicamente para desenhar". Essa conceituação traz uma abordagem teórico-filosófica da AI. Hoje, há definições que abarcam os ditames da tecnologia propriamente dita, a qual pode ser definida como:

A arte e a ciência de organizar e catalogar websites, intranets, comunidades online e software de modo que a usabilidade seja garantida. À medida que a informação prolifera de forma exponencial, a usabilidade vem se tornando o fator crítico de sucesso para websites e aplicações. Uma boa AI estabelece as fundações necessárias para que um sistema de informação faça sentido para seus usuários (interagentes) (MACEDO, 2013, não paginado).

Essa definição traduz o que a AI deve oferecer aos interagentes em termos de facilidade na busca e acesso à informação. Rosefeld e Morville (1998) asseveram que a AI tem o fito de facilitar a realização de tarefas e o acesso intuitivo a contextos e conteúdos virtuais.

De modo geral, Silva e Dias (2008, p. 4) comentam o objetivo da AI, ressaltando que ela serve para: "[..] atender às necessidades de informação dos usuários, através da organização da informação em websites, de forma que os usuários consigam encontrá-las e alcancem seus objetivos". De maneira sucinta, 
Artigos de Revisão

a AI tem a prerrogativa de combinar elementos da arquitetura e do design com o objetivo de ser uma ferramenta tecnológica de alta relevância na recuperação da informação, sendo capaz de disponibilizar no seu núcleo uma combinação de quatro segmentos complementares, além de elementos adicionais, os quais são apresentados no quadro a seguir:

Quadro 3-Componentes que fazem parte da AI

\begin{tabular}{|c|c|}
\hline ELEMENTOS & DESCRIÇÃO \\
\hline Organização & $\begin{array}{l}\text { É de responsabilidade do sistema de organização determinar o agrupamento e a } \\
\text { categorização das informações de um website. Nesse sentido, categorizar significa } \\
\text { agrupar coisas através de semelhanças. A categorização é um instrumento cognitivo de } \\
\text { princípio fundamental utilizado para simplificar a interatividade do indivíduo com o } \\
\text { ambiente. Dessa forma, esse componente da arquitetura de informação tem por função } \\
\text { definir as regras de classificação e ordenação das informações onde serão apresentados } \\
\text { os conteúdos oferecidos. }\end{array}$ \\
\hline Navegação & $\begin{array}{l}\text { O sistema de navegação especifica as maneiras de se navegar e de movimentação pelo } \\
\text { espaço informacional e hipertextual da Internet. Por meio desse sistema, existe a } \\
\text { possibilidade de mapeamento de novos percursos, a determinação da posição do usuário } \\
\text { e a possibilidade de se retornar à página inicial. Ele faz com que os usuários não se } \\
\text { sintam perdidos, o que pode gerar confusão, frustração e raiva, sentimentos que são } \\
\text { resultado de quando se descobre um ambiente novo sem saber aonde se pode chegar. }\end{array}$ \\
\hline Rotulagem & $\begin{array}{l}\text { Este sistema define as formas de representação e apresentação da informação a partir } \\
\text { da atribuição de rótulos aos conteúdos. O rótulo é a representação de um conjunto de } \\
\text { informações desenvolvida a partir de uma palavra (textual) ou ícone diferente } \\
\text { (iconográfico), usado para recuperar a informação digital e facilitar a navegabilidade do } \\
\text { usuário na página. }\end{array}$ \\
\hline Busca & $\begin{array}{l}\text { Determina as questões que o usuário pode fazer ao sistema e o conjunto de respostas a } \\
\text { serem obtidas. É usado para encontrar as informações na web presentes em qualquer } \\
\text { computador ligado à internet. Este sistema é utilizado em sites que possuem grande } \\
\text { volume de produção informacional para facilitar a busca do usuário. Um obstáculo a ser } \\
\text { superado nessa etapa é a dificuldade encontrada para localizar o grande número de } \\
\text { informações que são criadas a todo o momento, haja vista que esse fato dificulta a } \\
\text { indexação de todos os conteúdos apresentados. }\end{array}$ \\
\hline Elementos Adicionais & $\begin{array}{l}\text { A navegabilidade, objetividade e visibilidade são critérios utilizados ao se analisar o } \\
\text { conteúdo das informações de um website. A navegabilidade trata do tempo necessário } \\
\text { para o usuário realizar a recuperação da informação que necessita; a objetividade, o uso } \\
\text { da linguagem empregada pelo usuário no momento de sua pesquisa e a visibilidade } \\
\text { mostram a forma como as informações estão organizadas visualmente no site. }\end{array}$ \\
\hline
\end{tabular}

Fonte: Paiva (2013).

Esses componentes são o sustentáculo que formam a AI, no qual as diretrizes de cada elemento devem ser desenvolvidas visando sempre que os sujeitos possam: interagir e acessar a informação de que necessitam de maneira adequada e eficiente, almejando o atendimento das suas necessidades de informação e conhecimento.

$\mathrm{O}$ desenvolvimento de aplicativos mobile em bibliotecas utilizando os elementos da AI podem ser aplicados quando forem projetados, pois os componentes da AI são de cunho tecnológico, oferecendo a possibilidade de projetar uma tecnologia com modernismo que irá render custo-eficácia favorável para os interagentes.

\subsection{PREPAROS ESTRATÉGICOS PARA O DESENVOLVIMENTO DE APLICATIVOS EM BIBLIOTECAS}

Após a verificação de alguns elementos da arquitetura da informação que norteiam a construção de ambientes, produtos e serviços na web, espera-se aqui evidenciar algumas 
observações iniciais que os bibliotecários precisam levar em consideração ao propor um aplicativo para a sua biblioteca.

\subsubsection{Filosofia da mobilidade}

O primeiro deles é o entendimento da filosofia da mobilidade de serviços. Junto dos dispositivos móveis, os aplicativos aceleraram o modo como os indivíduos acessam, criam e compartilham conteúdo, sem necessariamente precisar de uma conexão integral à Internet. Isso traz novas conexões neurológicas e diferentes percepções de espaço e de tempo que chegam a influenciar, inclusive, o tradicional serviço de referência. Entender primeiramente isso amplia a visão do bibliotecário que for criar o seu aplicativo, algo que é comum para o público, mas dentro das bibliotecas ainda está em processo de desenvolvimento.

\subsubsection{Contexto}

Todo planejamento deve levar em consideração um contexto. Griggs, Bridges e Rempel (2009) apresentam três questões das quais os bibliotecários precisam ter as respostas antes de desenvolver um aplicativo: Qual o contexto de sua comunidade? Quais os objetivos daquele que acessa o aplicativo? Quais tarefas serão realizadas e não serão realizadas em um aplicativo?

Essas perguntas aceitam mais que uma resposta. Mapear toda a comunidade que a biblioteca atende (modos de interação, formas de acessar informação, como criam novos conhecimentos, quais suportes informacionais são mais utilizados, que tipo de linguagem utilizam com mais afinidade ao comunicar-se) ajuda a perceber como o aplicativo irá atuar e contribuir com o desenvolvimento das atividades propostas pela biblioteca.

\subsubsection{Desenvolvimento}

A etapa de desenvolvimento em si consiste de várias fases. Dependendo do contexto, da plataforma de desenvolvimento e da equipe envolvida, poderão ser acrescidas outras fases ou excluídas algumas das quais elencaremos nos próximos parágrafos ${ }^{1}$.

Uma vez que se tenha o conhecimento do uso de dispositivos móveis pela sua comunidade e qual a demanda informacional que costuma ser atendida nestes espaços, chega a fase de alinhar as ideias e uma prévia de uma interface. Em seguida, deve-se criar um wireframe,' que de acordo com Pereira (2008) é um "desenho básico que demonstra de forma direta a arquitetura de como o objeto final será de acordo com as especificações relatadas", que prototipe o seu aplicativo e um storyboard que mostre as ações que serão realizadas dentro do aplicativo. Ferramentas como HotGloo, Balsamiq e Moqups auxiliam nesta fase de desenvolvimento.

Importante destacar que o uso de wireframes é algo bastante tradicional dentro do trabalho de desenvolvimento, mas que vem sendo substituído por outras maneiras. Teixeira (2012) afirma que até pouco tempo atrás, um projeto era desenvolvido seguindo a construção de wireframes; posteriormente, de layouts e finalizava com mockups ${ }^{2}$ clicáveis; ou seja, três elementos para um mesmo produto. Segundo Stackoverflow (2014. Grifo do autor), o mockup é um "modelo mais detalhado do produto final, em que as questões estéticas são importantes e as funcionalidades básicas são demonstradas de uma forma estática". Dessa forma, o autor recomenda que o trabalho seja mais cooperativo entre os indivíduos envolvidos e sempre com um olhar na experiência do usuário (TEIXEIRA, 2012).

\footnotetext{
${ }^{1}$ Construído e adaptado a partir de Haselmayr (201?; 2013); Marinacci (2012); Lecheta (2015); Deitel, Deitel e Deitel (2015).
}

\footnotetext{
${ }^{2}$ Mockup (ou mock-up) é um "modelo mais detalhado do produto final, em que as questões estéticas são importantes e as funcionalidades básicas são demonstradas de uma forma estática”. (STACKOVERFLOW, 2014).
} 
Figura 1 - Exemplo de um esquema de storyboard

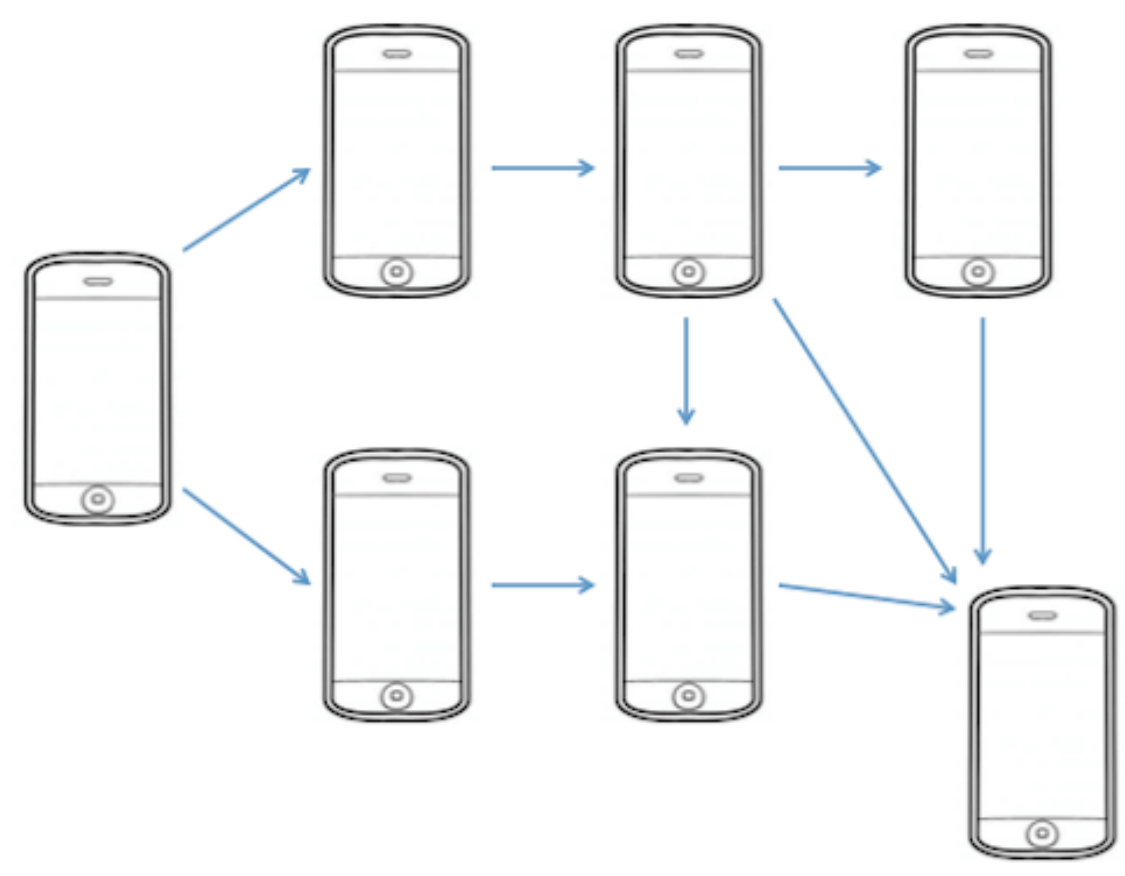

Fonte: Haselmayr (201?).

Com o protótipo criado, é o momento de disponibilizá-lo para testes e feedback. É importante que tudo seja registrado: dificuldades e facilidades de acesso, rapidez no retorno de solicitações, além de monitorar a usabilidade. Essa fase é para testar o protótipo, logo, não é necessário se preocupar com afinco sobre questões que tenham foco em design do aplicativo. Só depois de ter alcançado os propósitos elencados no planejamento do aplicativo, isto é, verificar se as ações programadas funcionaram, é que se trabalhará a interface gráfica.

A próxima fase do desenvolvimento é dedicada ao back end do aplicativo, um momento de pensar soluções para a configuração de servidores, bancos de dados, APIs (interface aberta de programação de aplicativos) e soluções de armazenamento dos dados que serão ali inseridos. Dependendo do número de atividades que o aplicativo se propõe a realizar, esses elementos receberão mais ou menos esforços técnicos. Enquanto isso, os designers se debruçam no detalhamento das telas desenhadas na fase do wireframe. É crucial um olhar atento para a experiência do usuário, previamente identificada também na fase do wireframe: cores, fontes, plano de fundo, número de toques, acessibilidade e outros elementos que facilitam o acesso à informação.

Novas fases foram completadas e novamente torna-se necessário realizar um teste do aplicativo, que agora está próximo do final de seu desenvolvimento. Todos os elementos gráficos para a interface já foram inseridos, bem como os textos. Utilizar ferramentas como Solidify e Framer permitirão testar os fluxos entre as telas e a funcionalidade dos elementos inseridos.

A última fase de desenvolvimento de um aplicativo é composta por duas atividades: manutenção e avaliação. Acompanhar constantemente o servidor é uma forma de prevenir futuros problemas de acesso e de alimentação de dados por parte dos interagentes. Já a avaliação propõe a melhora contínua do aplicativo, percebendo se é necessário um novo planejamento ou trabalhar na inovação do produto.

\section{CONSIDERAÇÕES FINAIS}

Os aplicativos móveis podem ser considerados como um marco tecnológico na disseminação da informação e da comunicação. As bibliotecas, como espaços 
envolvidos com estes elementos, precisam se adequar a esse contexto emergente e em expansivo crescimento, começando pela oferta de seu próprio aplicativo.

Em território brasileiro, as iniciativas de construção de aplicativos por bibliotecários ainda são tímidas. Esta seria uma lacuna do artigo que poderia ser investigada em outro texto: elencar as razões que limitam ou impossibilitam a criação de aplicativos em bibliotecas brasileiras, onde poderiam ser evidenciados diferentes ambientes (biblioteca pública, universitária, escolar, comunitária).

Aqui, o objetivo foi apresentar algumas observações que devem ser considerados no desenvolvimento de um aplicativo. Para isso, foi necessário trazer um pouco das realidades nacional e internacional com a finalidade de apontar algumas funcionalidades já em prática por profissionais.

Em seguida, em linhas gerais, evidenciouse uma abordagem teórica proveniente da arquitetura da informação que, por tratar de construir e melhorar serviços e produtos em ambientes web, é necessária ao se pensar o desenvolvimento de aplicativos. Para bibliotecários, essa é uma área em franca expansão, mas com poucos profissionais atuando.

Para finalizar, atendendo ao propósito do artigo, apresentam-se algumas observações para a criação de um aplicativo em biblioteca. A apresentação dá-se de maneira interligada com os elementos apresentados anteriormente em um formato de ciclo de vida, uma vez que se entende que um projeto como esse necessita de constante acompanhamento para atender sua comunidade de interagentes. Para estudos futuros, recomendamos a criação de critérios de avaliação de aplicativos em bibliotecas, tendo como elemento de sustento as contribuições da arquitetura da informação.

\title{
DEVELOPMENT OF LIBRARY MOBILE APPLICATIONS FROM INFORMATION ARCHITECTURE ASPECTS
}

\begin{abstract}
The text discusses about how mobile applications can be used in libraries, aiming at a closer relationship with the interacting, research has in its scope as a general abrangence: to show what the observations to develop a mobile application for library; as to the specific segments we have the following configuration: to show the context for insertion applications in libraries and explain how the information architecture is used in applications; as the methodological and operational route was chosen at first by the literature, after the research has the configuration exploratory character, in view of their potential contribution feature to the Library Science community, raises concern as: How libraries can develop attractive and efficient applications for interacting? Finally, the research aims to provide the observations as regards the development of application for mobile devices, in which these can be factors that provide functionality and visibility for libraries.
\end{abstract}

Keywords: Information and Communication Technology. Mobile apps. Libraries. Mobile devices.

\section{REFERÊNCIAS}

BARROS, Moreno. Aplicativos mobile em bibliotecas brasileiras. Bibliotecários Sem Fronteiras. (blog), Belém, 12.08.2012. Disponível em: <https://bsf.org.br/2012/07/10/aplicativosapp-biblioteca-mobile-android-ios/>. Acesso em: 2 jun. 2016.
BASTOS, Tássia Rosa. Aplicativos para dispositivos móveis e seu uso em bibliotecas: uma visão das experiências em âmbito internacional. 2014. 84 f. (Trabalho de Conclusão de Curso) - Curso de Biblioteconomia, Faculdade de Informação e Comunicação, Universidade Federal de Goiás, Goiânia, 2014. Disponível em: <https://repositorio.bc.ufg.br/bitstream/ri/108 
06/1/TCC\%20-\%20Biblioteconomia\%20$\% 20 \mathrm{~T} \% \mathrm{C} 3 \% \mathrm{~A} 1 \mathrm{ssia} \% 20 \mathrm{Rosa} \% 20 \mathrm{Bastos} \% 20$ >. Acesso em: 5 jun. 2016.

BRAGA, João Alberto de Oliveira. Aspectos relevantes para a seleção de metodologia adequada à pesquisa social em Ciência da Informação. In: MUELLER, Suzana Pinheiro Machado. Métodos para a pesquisa em Ciência da Informação. Brasília, DF: Thesaurus, 2007. p. 17-38.

CASTELLS, Manuel. A sociedade em rede: do conhecimento à política. In: CASTELLS, Manuel; CARDOSO, Gustavo (Org.). A sociedade em rede: do conhecimento à ação política. Lisboa: Imprensa Nacional, 2005.

CORREA, Elisa C. D. Usuário, não! Interagente: proposta de um novo termo para um novo tempo. Encontros Bibli: revista eletrônica de biblioteconomia e ciência da informação, Florianópolis, v. 19, n.41, p. 2340, set./dez., 2014. Disponível em: <https://periodicos.ufsc.br/index.php/eb/articl e/view/1518-2924.2014v19n41p23/28292>. Acesso em: 31 maio 2016.

DEITEL, P. J.; DEITEL, H. M.; DEITEL, A. Android para programadores: uma abordagem baseada em aplicativos. 2. ed. Porto Alegre: Bookman, 2015.

GRIGGS, K.; BRIDGES, L. M.; REMPEL, H. G. library/mobile: tips on designing and developing mobile web site. The code $\{4\}$ lib journal, v. 8, 2009. Disponível em: <http://journal.code4lib.org/articles/2055>. Acesso em: 21 jul. 2016.

HASELMAYR, M. A 12-step guide to building your very first mobile app: part 1 . Publicado em: [201?]. Disponível em: $<$ https://www.allbusiness.com/12-step-guideto-building-your-first-mobile-app-111931.html\#.UoUPqqW6LII>. Acesso em: 21 jul. 2016.

HASELMAYR, M. How to build your first mobile app in 12 steps: part 2. Publicado em: 14 nov. 2013. Disponível em: $<$ http://www.forbes.com/sites/allbusiness/201 3/11/14/how-to-build-your-first-mobile-appin-12-steps-part-2/\#2380fb785bb9>. Acesso em: 21 jul. 2016.
LAKATOS, Eva Maria; MARCONI, Marina de Andrade. Fundamentos da metodologia cientifica. 6. ed. São Paulo: Atlas, 2005.

LECHETA, R. R. Google Android: aprenda a criar aplicações para dispositivos móveis com o Android SDK. 5. ed. São Paulo: Novatec, 2015.

LIMA-MARQUES, M.; MACEDO, F.L. O. Arquitetura da Informação: base para a Gestão do Conhecimento. In:

TARAPANOFF, K. (Org.). Inteligência, informação e conhecimento. Brasília, DF: IBICT/UNESCO, 2006.

MARINACCI, J. Construindo aplicativos móveis com Java. São Paulo: Novatec, 2012.

NEIL, Theresa. Padrões de design para aplicativos móveis. São Paulo: Novatec, 2010.

PAIVA, Rodrigo Oliveira de. Estudo da rede de informação legislativa e jurídica Lexml Brasil sob o prisma da arquitetura da informação. 119 f. 2013. (Trabalho de Conclusão de Curso) - Graduação em Biblioteconomia, Faculdade de Biblioteconomia, Instituto de Ciências Sociais Aplicadas, Universidade Federal do Pará, Belém, 2013.

PEREIRA, A. P. O que é wireframe?

Tecmundo. Publicado em: 18 nov. 2008.

Disponível em:

<http://www.tecmundo.com.br/programacao/ 976-o-que-e-wireframe-.htm>. Acesso em: 25 jul. 2016.

ROSEFELD, Louis; MORVILLE, Peter. Information Architecture for the World Wide Web. Sebastopol: O’Reilly, 1998.

SILVA, Patrícia Maria da; DIAS, Guilherme Ataíde Dias, A arquitetura da informação centrada no usuário: estudo do website da biblioteca virtual em saúde (Bvs). Encontros Bibli: revista eletrônica de biblioteconomia e ciência da informação, Florianópolis, n. 26, 2. sem. 2008.

STACKOVERFLOW. Quais são as diferenças entre wireframe, protótipo e mockup? Publicado em: 2014. Disponível em: 
<http://pt.stackoverflow.com/questions/21677 /quais-são-as-diferenças-entre-wireframeprotótipo-e-mockup>. Acesso em: 22 jul. 2016.

TEIXEIRA, Fabricio. O começo do fim dos wireframes. Blog de AI. Publicado em: 2012. Disponível em: <

http://arquiteturadeinformacao.com/userexperience/o-comeco-do-fim-doswireframes/>. Acesso em: 22 jul. 2016.
TERUEL, Evandro Carlos. Web mobile. São Paulo: Ciência moderna, 2010.

VIEIRA, J. M. L.; PINHO, F. B. A. A contribuição da organização e da visualização da informação para os sistemas de recuperação de informação. Informação \& Informação, v. 20, n. 1, 2015. Disponível em:

<http://www.brapci.ufpr.br/brapci/v/17754>. Acesso em: 29 maio 2016. 